\title{
Analysis of stress field and determination of safe mud window in borehole drilling (case study: SW Iran)
}

\author{
Mohammad Abdideh • Mohammad Reza Fathabadi
}

Received: 15 November 2011 / Accepted: 3 March 2013/Published online: 29 March 2013

(c) The Author(s) 2013. This article is published with open access at Springerlink.com

\begin{abstract}
Having information on the magnitude and direction of stress in high depth is of critical importance in geology and engineering sciences. Of uppermost applicants of stress data in oil industry, determination of borehole stability can be mentioned. To achieve scientific and engineering solutions for problems such as optimal mud weight, stable routes, casing, sand production, etc., precise information on stress position in depth is required. So, the present study is aimed to determine magnitude and directions of in situ stresses in a borehole located in south western Iran. Minimum horizontal stress is observed along the direction of borehole breakout and maximum horizontal one, along the direction of derived from drilling. Direction of these two horizontal stresses is determined by means of image log. Position of in situ stresses in the under-study field is of normal stress regime. Having determined direction and magnitude of in situ stresses, we find safe mud window to design a stable borehole.
\end{abstract}

Keywords Reservoir rock - Geomechanics - Stress field · Well bore stability $\cdot$ Safe mud window $\cdot$ Petrophysical data

\section{Introduction}

Hydrocarbon geomechanic reservoirs play daily-increasing important role in evaluation and development of oil and gas fields. Geomechanics is, indeed, a field of science exploring and analyzing earth behavior against stresses. Stresses are of two types: natural stress inside the earth and the

M. Abdideh $(\bowtie) \cdot$ M. R. Fathabadi

Department of Petroleum Engineering, Omidiyeh Branch,

Islamic Azad University, Omidiyeh, Iran

e-mail: abdideh@iauo.ac.ir other, those induced by men during various operations like drilling. So, as implied by the term "Geomechanics," keys to physical and mechanical problems resulted from materials operating in various depth of the earth and from the existing stresses can be found in domain of this science. However, chemical disturbance and problems related with it, should be studied and investigated by other sciences especially geo mechanics (Amadie and Stephansson 1997). For the purpose of analyzing borehole instability, direction and magnitude of in situ is of great criticality.

In situ stresses are usually expressed in terms of a tensor of six components. However, in oil field studies, the stresses are determined only for three principal components of the stress: a vertical component $\left(\sigma_{\mathrm{v}}\right)$, and two minimum and maximum horizontal stress components $\left(\sigma_{\mathrm{H}}\right.$ and $\left.\sigma_{\mathrm{h}}\right)$. Accordingly, a number of direct and indirect methods (empirical equations) have been presented to determine the magnitude of stresses in oil reservoirs in great depth. However, the principal horizontal stresses, especially $\sigma_{\mathrm{H}}$, are still major challenge to be determine in geomechanical oil field studies (Zobac et al. 2003).

During drilling, we may encounter two main problems in borehole stability: breakout (BO) and drilling induced tensile fracture (DITF) that may lead to fishing, stuck pipe, sidetracking, reaming and fluid loss (Nguyen et al. 2004), all of which can be resolved through determination of safe mud window for borehole drilling. Safe mud window consists of a pressure with the magnitude between pore pressure and minimum horizontal stress. In situ stress field should be analyzed so as to determine safe mud window. Perfect illustration of stress field in the earth only requires magnitude and direction of main stresses to be determined.

Minimum horizontal stress is observed along the direction of borehole breakout and maximum horizontal one, along the direction of DITFs derived from drilling. 
Direction of these two horizontal stresses is determined by means of image log. Magnitude of main stress is obtained through integration of density log. Due to the absence of leak-off test data, magnitude of minimum and maximum horizontal stresses is estimated via equations available.

\section{Discussion}

The field under study consists of three reservoirs of Asmari, Bangestan and Khami, of which the first two are oil reservoirs and the latter, a gas reservoir. The big Asmari reservoir is complicated and heterogeneous in terms of reservoir rock features. Lithologic status of the considered borehole in Asmari structure is determined applying cross plots of (photoelectric and Neutron) density logs. Both cross plots appropriately reveal that the dominant lithology is carbonate (dolomite enjoys higher percentage than that of limestone); furthermore, amount of sandstone found is insignificant when compared to the abundance of carbonate. Figure 1 shows the above-mentioned cross plots.

\section{Direction of main stresses}

Breakouts and DITFs of borehole walls appropriately reveal stress direction. In almost vertical boreholes, BO axis is straightly along minimum horizontal stress and DITF, along maximum horizontal stress (Tingay 2008). Therefore, these fractures can be applied to determine stress direction. Fracture direction can also be determined by means of geophysical logs such as televiewer ultrasonic borehole (BHTV), formation micro imager (FMI), and Caliper Logs (Fig. 2).

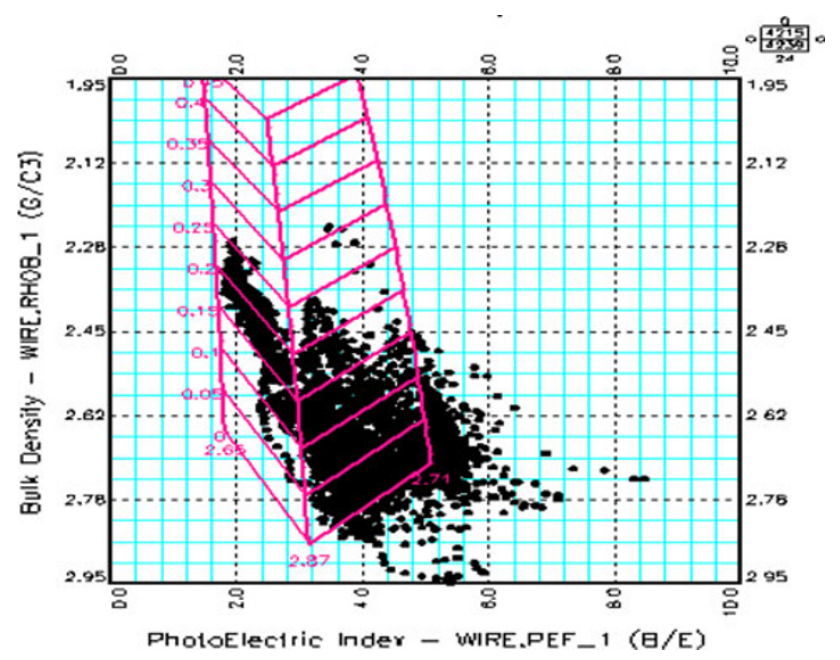

Fig. 1 Variation of lithology in oil field
Magnitude of in situ stresses

Assuming verticality of one component of the main stress, vertical boreholes are parallel to vertical main stress $\left(S_{\mathrm{v}}\right)$. Therefore, $S_{\text {Hmax }}$ and $S_{\text {hmin }}$ will be two other main stresses. Vertical stress is obtained through integration of rock density from surface to the considered depth:

$s_{v}=\int_{0}^{z} \rho(z) g \mathrm{~d} z \cong \bar{\rho} g z$.

where $\rho(z)$ is rock density which itself is a function of depth; $g$ represents gravity constant and $\bar{\rho}$ stands for the average density. In the under study borehole, $\bar{\rho}$ has been assumed equal to $2.56 \frac{\mathrm{g}}{\mathrm{cm}^{3}}$.

Magnitude of $s_{\mathrm{hmin}}$ can be measured via different methods like hydraulic fracture, leak-off tests, micro-fracture test and mini-fracture test. Willis and Hubbert (1957) presented a thorough discussion on that hydraulic fracture, in which a fracture developed, extended vertical to the direction of minimum horizontal stress. The reason they offered was that the work done to open a crack of a given magnitude was proportionate to the stress vertically imposed to crack plane against opening magnitude.

Another method used to calculate the horizontal stresses is based on the poroelastic theory. In a tectonically active basin, tectonic stresses and strains arise from tectonic plate movement. If tectonic strains are applied to rock formations, these strains add a stress component in an elastic rock. The poroelastic horizontal strain model takes tectonic strains into account, and therefore accommodates anisotropic horizontal stresses (Blanton and Olson 1999).

$$
\begin{aligned}
& \sigma_{\mathrm{h}}=\frac{v}{1-v} \sigma_{\mathrm{v}}-\frac{v}{1-v} \alpha p_{\mathrm{p}}+\alpha p_{\mathrm{p}}+\frac{E}{1-v^{2}} \varepsilon_{\mathrm{x}}+\frac{v E}{1-v^{2}} \varepsilon_{\mathrm{y}} \\
& \sigma_{\mathrm{H}}=\frac{v}{1-v} \sigma_{\mathrm{v}}-\frac{v}{1-v} \alpha p_{\mathrm{p}}+\alpha p_{\mathrm{p}}+\frac{E}{1-v^{2}} \varepsilon_{\mathrm{y}}+\frac{v E}{1-v^{2}} \varepsilon_{\mathrm{x}}
\end{aligned}
$$

where $\sigma_{\mathrm{h}}$ is minimum horizontal stress, $\sigma_{\mathrm{H}}$ represents maximum horizontal stress and $v$ stands for Poisson's ratio, $\sigma_{\mathrm{v}}$ is vertical stress, $\alpha$ indicates Biot coefficient, $\operatorname{Pr}$ stands for pore pressure and $E$ for young's modulus, and finally $\varepsilon_{\mathrm{x}}$ and $\varepsilon_{\mathrm{y}}$ present strain toward minimum and maximum horizontal stresses, respectively.

Elasticity coefficients can be obtained applying empirical relations and also measurement well logs. Gradient of the average pore pressure in the under examination borehole equals $0.365 \mathrm{psi} / \mathrm{ft}$; Biot coefficient amounts to 1 and $\varepsilon_{\mathrm{x}}$ and $\varepsilon_{\mathrm{y}}$ are considered 1.5 and 1 , respectively.

$v_{\mathrm{dyn}}=\frac{1 / 2\left(\frac{\Delta t_{\mathrm{s}}}{\Delta t_{\mathrm{c}}}\right)^{2}-1}{\left(\frac{\Delta t_{\mathrm{s}}}{\Delta t_{\mathrm{c}}}\right)^{2}-1}$. 
Fig. 2 Identification of DITF and BO using FMI log

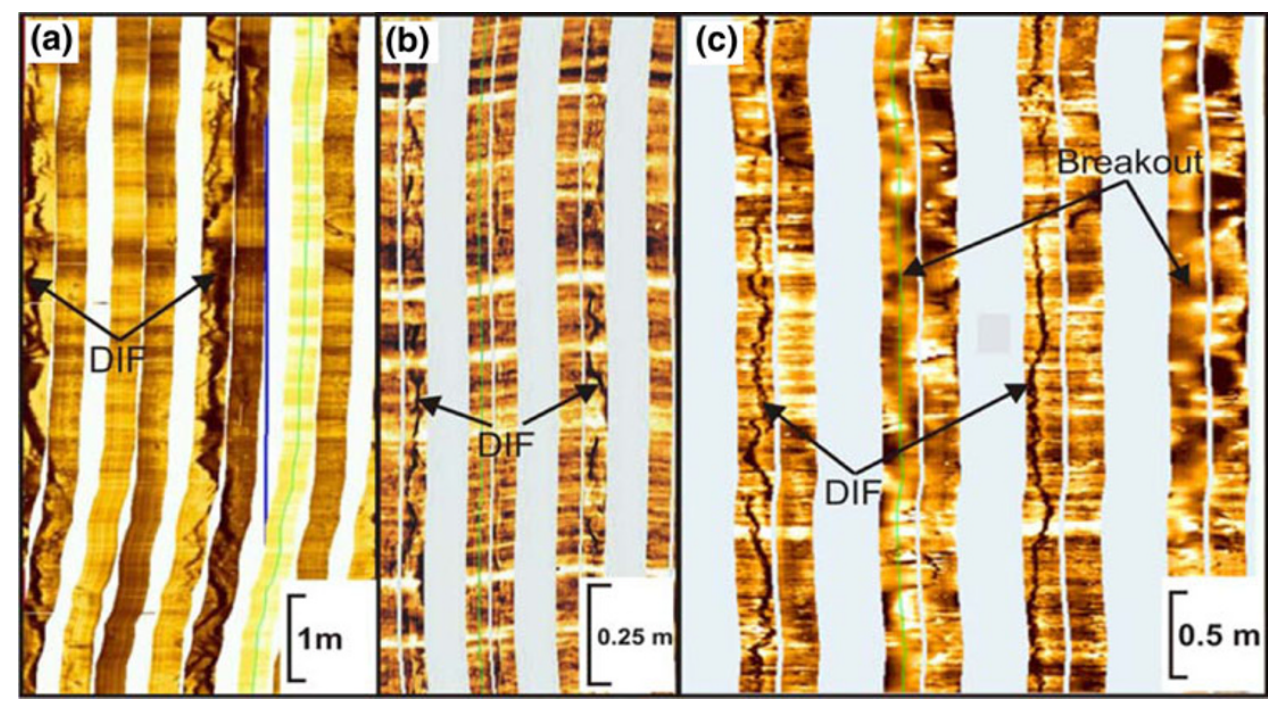

$E_{\mathrm{dyn}}=\frac{\rho_{\mathrm{b}}\left[3-4\left(\frac{\Delta t_{\mathrm{c}}}{\Delta t_{\mathrm{s}}}\right)^{2}\right]}{\Delta t_{\mathrm{s}}^{2}-\Delta t_{\mathrm{c}}^{2}}$

where $\Delta t_{\mathrm{s}}$ is the slowness of shear wave $\left(\frac{\mathrm{s}}{\mathrm{km}}\right), \Delta t_{\mathrm{c}}$ represents slowness of compression wave $\left(\frac{\mathrm{s}}{\mathrm{km}}\right), \rho_{\mathrm{b}}$ stands for density $\left(\frac{\mathrm{g}}{\mathrm{cm}^{3}}\right), v_{\text {dyn }}$ is dynamic Poisson's ratio, and $E_{\text {dyn }}$ indicates dynamic young's modulus (Gpa).

Dynamic data cannot directly be utilized to develop mechanical models. So, they should be first converted into static data through some calculation changes made and then used in geomechanical model. Poisson's ratio and static young's modulus are both calculated via the following relations in SW Iran. The results show good conformity with laboratorial data:

$v_{\text {sat }}=0.7 v_{\text {dyn }}$

$E_{\text {sta }}=0.414 E_{\text {dyn }}-1.0593$
In case rock resistance is more than stresses induced, borehole will be a stable one; otherwise, there will be a fracture. Furthermore, borehole instability lengthens drilling period and consequently increases borehole drilling costs.

For a safe mud window to be obtained, mud weight should be something between pore pressure and minimum horizontal stress. Mud weight less than structure pressure results in fluid eruption and fluid flows from reservoir into the well. In the event mud pressure exceeds minimum horizontal stress, DITFs develop and we will have mud loss. Range of stable mud window is something between least drilling mud weight (to prevent breakout) and minimum horizontal stress. From geomechanical point of view, stable mud window keeps borehole safe against DITFs and/ or stuck pipes which happen due to high mud weight as well as BOs which result from low mud weight (Al-Ajmi and Zimmerman 2006). Safe and stable mud weight windows have been shown in Fig. 3.

\section{Borehole stability}

Borehole instability factors are generally of three types: mechanical factors, chemical factors or a combination of these two. Mechanical factors mostly depend on inappropriate mud weight (too light or too heavy) and improper drilling methods (drilling extent, pipes' moment and vibration, and lifting pipes up and down), whereas chemical factors are dramatically influenced by drilling mud, that is to say, improper mud and insufficient inhibitors. Of course, in most cases borehole instability is the simultaneous result of chemical and mechanical factors (Hawkes and Mclellan 2002).

Above all, borehole instability relies on stress distribution and centralization around the drilled borehole.

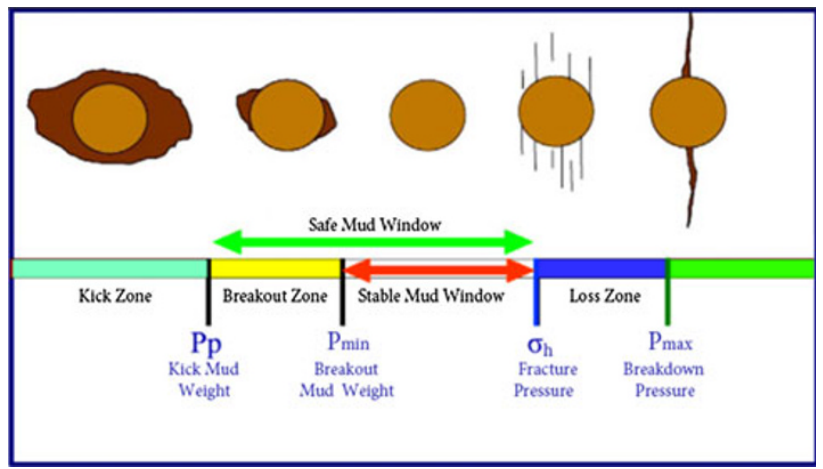

Fig. 3 Safe and stable mud weight windows

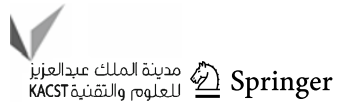


Stress around a vertical borehole

Underground structures are always under pressure because of vertical and tectonic stresses. When a borehole is drilled inside a structure, some parts of (rock) materials are missed. Borehole's side walls are maintained only by fluid pressure. Since this fluid pressure is not consistent with in situ structure stresses, new stress redistribution occurs around borehole that may lead to rock fracture. Therefore, identification of stresses existent around a borehole is of great importance to examine borehole problems. There are two common types of borehole fracture: first one is drilling induced tension fracture (DITF) and the second one, with $90^{\circ}$ of difference, is called breakout. In a substance with linear elastic behavior, centralization of bigger stress occurs on borehole wall, so borehole fracture is expected to start from this area.

Drilling operation disturbs the equilibrium condition of in situ stresses. Therefore, new (induced) stresses are provided around the wellbore. If the wellbores are affected by induced stresses, they have some failures. Thus, after the estimation of the principal stresses, they are converted into the induced stresses using existing relations. Stress concentration around a vertical wellbore, which has been drilled in parallel with the principal vertical stress and is in isotropic conditions in elastic environment, was described by Kirsch equations (Kirsch 1898).

$$
\begin{aligned}
\sigma_{\mathrm{rr}}= & \frac{1}{2}\left(\sigma_{\mathrm{H}}+\sigma_{\mathrm{h}}-2 P_{\mathrm{p}}\right)\left(1-\frac{R^{2}}{r^{2}}\right)+\frac{1}{2}\left(\sigma_{\mathrm{H}}-\sigma_{\mathrm{h}}\right) \\
& \times\left(1-4 \frac{R^{2}}{r^{2}}+3 \frac{R^{4}}{r^{4}}\right) \cos 2 \theta+\frac{\Delta P R^{2}}{r^{2}} \\
\sigma_{\theta \theta}= & \frac{1}{2}\left(\sigma_{\mathrm{H}}+\sigma_{\mathrm{h}}-2 P_{\mathrm{p}}\right)\left(1+\frac{R^{2}}{r^{2}}\right)-\frac{1}{2}\left(\sigma_{\mathrm{H}}-\sigma_{\mathrm{h}}\right) \\
& \times\left(1+3 \frac{R^{2}}{r^{2}}\right) \cos 2 \theta-\frac{\Delta P R^{2}}{r^{2}} \\
\sigma_{\mathrm{zz}}= & \sigma_{\mathrm{V}}-2 v\left(\sigma_{\mathrm{H}}-\sigma_{\mathrm{h}}\right) \cos 2 \theta-P_{\mathrm{P}}
\end{aligned}
$$

where $\theta$ : angle measured from the azimuth of $\sigma_{\mathrm{H}}, \sigma_{\theta \theta}$ : effective tangential stress, $\sigma_{\mathrm{rr}}$ : effective redial stress and $\sigma_{\mathrm{zz}}$ : effective vertical stress.

$\sigma^{\Delta T}$ represents thermal stresses arising from the difference between the mud temperature and formation temperature. This will be ignored for the moment.

Mathematically, effective stresses around a vertical borehole of the radius $R$ are defined in cylinder coordinate system of axis as follows:

$$
\begin{aligned}
& \sigma_{\theta \theta} \max =3 S_{\mathrm{H} \text { max }}-S_{\mathrm{h} \text { min }}-P_{\mathrm{w}}-P_{\mathrm{p}} \\
& \sigma_{\theta \theta} \min =3 S_{\mathrm{h} \text { min }}-S_{\mathrm{H} \text { max }}-P_{\mathrm{w}}-P_{\mathrm{p}} \\
& \sigma_{\mathrm{zz}} \max =S_{\mathrm{v}}+2 v\left(S_{\mathrm{H} \text { max }}-S_{\mathrm{h} \text { min }}\right)-P_{\mathrm{p}}
\end{aligned}
$$

\begin{tabular}{|c|c|c|}
\hline \multicolumn{3}{|c|}{ Multiple modes of tensile failure } \\
\hline \multicolumn{3}{|l|}{ Modes } \\
\hline \multirow{2}{*}{$\begin{array}{l}\sigma_{\mathrm{zz}}=\sigma_{3} \\
\sigma_{\theta \theta}=\sigma_{3}\end{array}$} & $\begin{array}{l}\Delta=\sigma_{\mathrm{zz}}-\mathrm{T}>0 \\
P_{\mathrm{m}}>-\left[\sigma_{\mathrm{V}}+\sigma_{\mathrm{h}}\right. \\
\left.(2 \mathrm{v}-3)+\sigma_{\mathrm{H}}(2 \mathrm{v}-3)\right]\end{array}$ & horizontal (HOR) \\
\hline & $\begin{array}{l}\Delta=\sigma_{\theta \theta}-T>0 \\
P_{\mathrm{m}}<3 \sigma_{\mathrm{h}}-\sigma_{\mathrm{H}} \\
-P_{\mathrm{P}}-T\end{array}$ & Vertical (VER): \\
\hline$\sigma_{\mathrm{rr}}=\sigma_{3}$ & $\begin{array}{l}\Delta=\sigma_{\mathrm{rr}}-T>0 \\
P_{\mathrm{m}}>P_{\mathrm{P}}+T\end{array}$ & Cylindrical (CYL) \\
\hline \multicolumn{3}{|c|}{ Multiple modes of compressive failure } \\
\hline$\sigma_{1} \quad \sigma_{2}$ & $\sigma_{3}$ & Modes \\
\hline$\Sigma_{\theta \theta} \quad \sigma_{\mathrm{zz}}$ & $\sigma_{\mathrm{rr}}$ & $\begin{array}{l}\text { Wide breakout (WBO): } \\
\text { conventional breakout }\end{array}$ \\
\hline$\sigma_{\theta \theta} \quad \sigma_{\mathrm{rr}}$ & $\sigma_{z z}$ & $\begin{array}{l}\text { Low angle echelon (LAE): } \\
\text { requires high mud weights. } \\
\text { Failed rock will not fall into } \\
\text { the wellbore as } \sigma_{\mathrm{rr}} \equiv \sigma_{2}\end{array}$ \\
\hline$\sigma_{\mathrm{zz}} \quad \sigma_{\mathrm{rr}}$ & $\sigma_{\theta \theta}$ & $\begin{array}{l}\text { High angle echelon (HAE): } \\
\text { forms on opposite side of well } \\
\text { as a conventional breakout but } \\
\text { the failed rock will not fall } \\
\text { into the wellbore as } \sigma_{\mathrm{rr}} \equiv \sigma_{2}\end{array}$ \\
\hline$\sigma_{\mathrm{zz}} \quad \sigma_{\theta \theta}$ & $\sigma_{\mathrm{rr}}$ & $\begin{array}{l}\text { Shallow knockout (SKO): } \\
\text { results in failure all the way } \\
\text { around the wellbore }\end{array}$ \\
\hline$\sigma_{\mathrm{rr}} \quad \sigma_{\mathrm{zz}}$ & $\sigma_{\theta \theta}$ & $\begin{array}{l}\text { Narrow breakout }(\mathrm{NBO}) \text { : } \\
\text { requires unreasonably high } \\
\text { mud weights. }\end{array}$ \\
\hline$\sigma_{\mathrm{rr}} \quad \sigma_{\theta \theta}$ & $\sigma_{\mathrm{zz}}$ & $\begin{array}{l}\text { Deep knockout }(\mathrm{SDKO}) \text { : } \\
\text { requires unreasonably high } \\
\text { mud weights }\end{array}$ \\
\hline
\end{tabular}

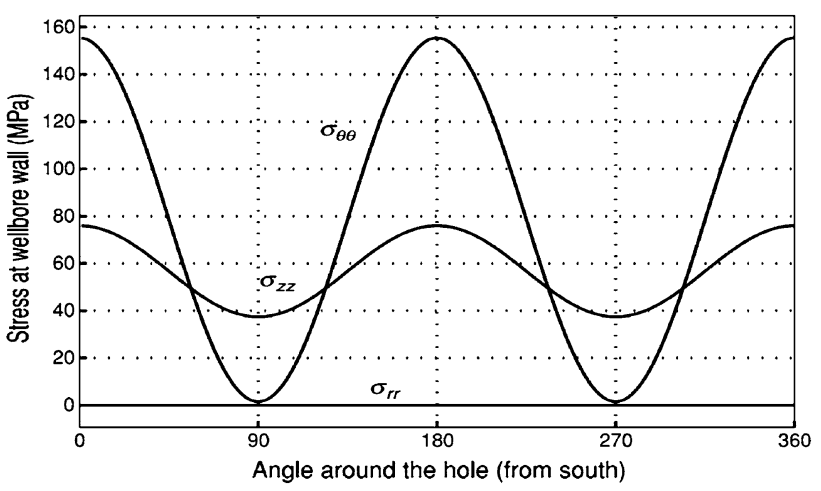

Fig. 4 Variation of effective principal stresses around a vertical wellbore as a function of azimuth

Table 1 Multiple modes of wellbore failure

$\sigma_{1}, \sigma_{2}$ and $\sigma_{3}$ maximum, mean and minimum stresses, $\sigma_{\mathrm{H}}$ and $\sigma_{\mathrm{h}}$ maximum and minimum horizontal stresses, $\theta$ angle measured from the azimuth of $\sigma_{\mathrm{H}}, P_{\mathrm{P}}$ and $P_{\mathrm{m}}$ pore and mud pressure, $\sigma_{\theta \theta}, \sigma_{\mathrm{rr}}$ and $\sigma_{\mathrm{zz}}$ tangential, redial and vertical effective stresses 


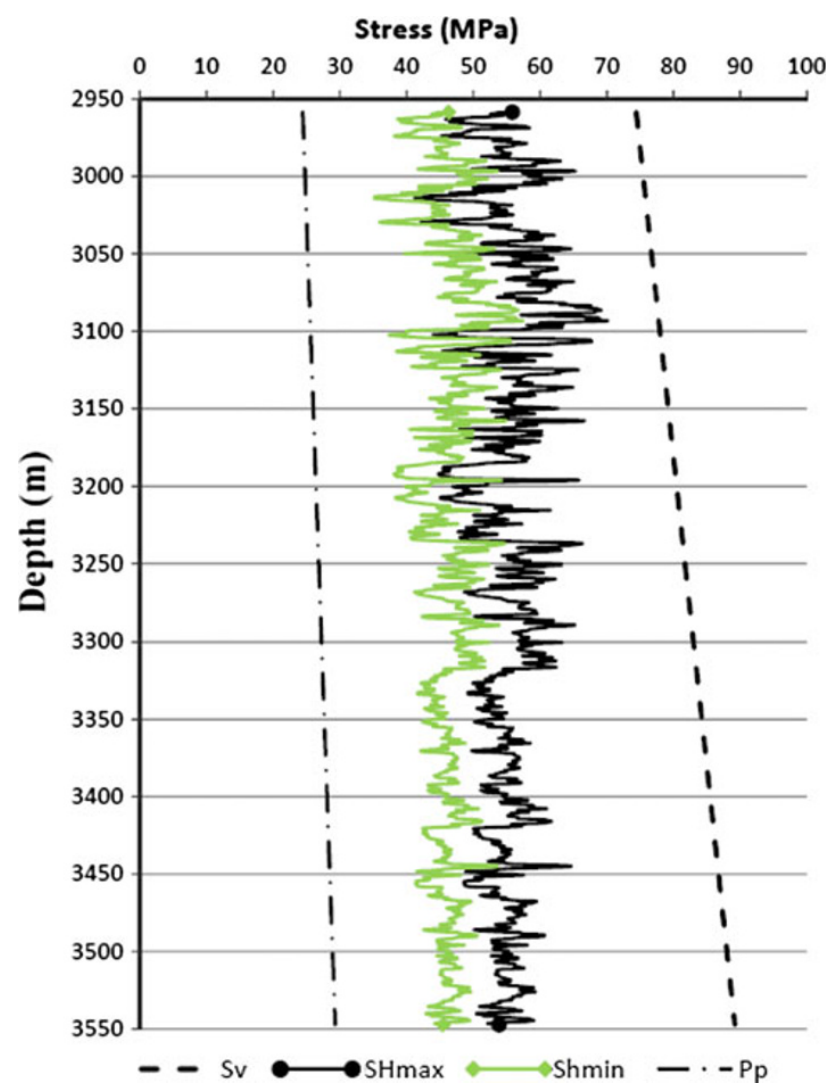

Fig. 5 Stress field and determination of safe mud window in borehole

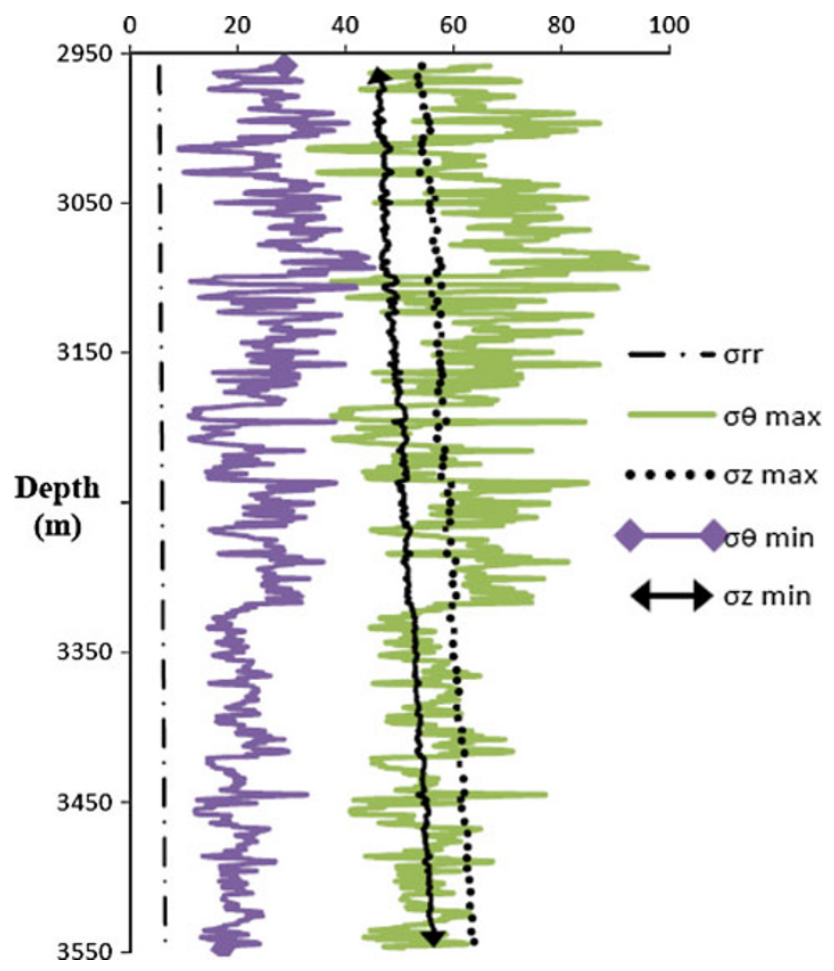

Fig. 6 Induced stress around borehole $\sigma_{\mathrm{zz}} \min =S_{\mathrm{v}}-2 v\left(S_{\mathrm{H} \max }-S_{\mathrm{h} \min }\right)-P_{\mathrm{p}}$

Considering fracture mechanics science, DITFs vertical to the main stress are minimum, and maximum along main stress (Fig. 4). If tangential stress is less than rock tension resistance, we will have a DITF and if it is greater than rock pressure resistance, a breakout will occur.

Depending on the status of the three components of stresses, 6 modes of shear failure, and 3 modes of tensile failure may occur around the wellbore (Table 1) (Fjaer et al. 2008). Because of the typical depth of oil reservoirs, the most common types of failure are of breakout and vertical tensile failure.

\section{Conclusion}

In this paper, the stresses were determined using the poroelastic method and based on petrophysical data. The result of this method shows relative compliance with the stress that was calculated on the basis of the width of the breakout and rock strength. The wellbores affected by these stresses are mostly stable, with no severe and extensive failures. The safe mud weight window was determined based on the estimated stress profiles. This mud window showed that in some depth, the used mud pressure is not appropriate and cause the limited failures.

It should be noted that in the studied field, there are other important factors in causing the failure such as collisions of the drill string with the wellbore, sudden decrease of drilling mud pressure and the presence of fractures.

Stress regime existing in under examination borehole is of normal type. Stress position and pore pressure, as shown in Figs. 5 and 6, are determined to the extent of safe mud window located somewhere between pore pressure and minimum horizontal stress. Considering type of stress field, in case of horizontal drilling it is recommended that optimal drilling route is along minimum horizontal stress.

Open Access This article is distributed under the terms of the Creative Commons Attribution License which permits any use, distribution, and reproduction in any medium, provided the original author(s) and the source are credited.

\section{References}

Al-Ajmi AM, Zimmerman RW (2006) Stability analysis of vertical boreholes using the Mogi-Coulomb failure criterion. Int J Rock Mech Mini Sci 43:1200-1211

Amadie B, Stephansson O (1997) Rock stress and its measurement, 1st edn. Chapman and Hall, London

Blanton TL, Olson JE (1999) Stress magnitudes from logs-effects of tectonic strains and temperature. SPE Res Eval Eng 2(1):62-68

Fjaer E, Holt RM, Horsrud P, Raaen AM, Risnes R (2008) Petroleum related rock mechanics, 2nd edn. Elsevier, Amsterdam 
Hawkes CD, Mclellan PJ (2002) Coupled modeling of borehole stability and multiphase flow for under balanced drilling, SPE pp 74447

Hubbert MK, Willis DG (1957) Mechanics of hydraulic fracturing. Pet Trans AIME 210:53-63

Kirsch G (1898) Die theorie der elastizitat und die bedurfnisse der festigkeitslehre. Z Ver Dtsch Ing 42(29):797-807

Nguyen Binh T, Tomochica T, Akihiko O (2004) In situ stress and pore pressure fields in the North Cuu Long Basin, Offshore Vietnam, SPE pp 87055
Tingay M (2008) Borehole breakout and drilling-induced fracture analysis from image logs. World stress map project. Guidelines: image logs

Zoback MD, Barton CA, Brudy M, Castillo DA, Finkbeiner T, Grollimund BR, Moos DB, Peska P, Ward CD, Wiprut DJ (2003) Determination of stress orientation and magnitude in deep wells. Int J Rock Mech Mini Sci 40:1049-1076 